\title{
Discussion on the Design Practice for Culture of Central China in Urban Architecture
}

\author{
Ya'nan Yang \\ Huanghe Science and Technology College \\ Zhengzhou, China
}

\begin{abstract}
As an important founder of Chinese culture, Central Plain Culture is legitimate, compatible, radiate and innovative. It is based on agricultural society and natural economy, takes blood clan relationship as a link and forms an unique architectural type and regional culture. While this kind of source root culture with Mother nature deeply influenced living environment of the inhabitants of the Central Plains Area. The paper takes Kang Baiwan Manor for example, analyzing the characteristics of site selection, material, technology and skills from spatial arrangement, architectural structure and decorative patterns to conclude scientific outlook of adjusting measures to differing conditions and the Nationalism focusing on "Fu". Widely accepted vernacular cultures with a rich background ingeniously applying to Contemporary urban architecture, it is bound to be strongly identifiable and unique.
\end{abstract}

Keywords-culture of Central China; residential buildings; Kang Baiwan Manor; rural concept; urbanization

\section{INTRODUCTION}

Located in central plain of China, the Central Plain Culture formed specific material culture, system culture, ideology and life style. It is a settled but specific living structure. The Central Plains cultures, once in the ancient Kyushu "Yu state", Henan as the main hinterland today, is one of the Chinese culture foundations. It is based on agricultural society and natural economy, takes blood clan relationship as a link and forms characteristics of legitimacy, compatibility, radiance and innovativeness.

In Henan area, the development of architectures with central characteristic has a particular historical background. Except two big traditional messuages Kang Baiwan Manor and Liu Zhenhua Manor in Gongyi, there emerged building types that integrated Chinese culture and western cultures and carried the characteristics of traditional cultures and national features. Such excellent architectures are auditorium, Historic building and press of Henan University in Kaifeng in Henan province.

If we want to inherent the nature of traditional architectures, we can't only disassemble their architectural elements and then put it into our practice, we should inherent

This paper was one phased research fruits of The Department of science and technology of Zhengzhou, Henan province in 2014 " research on the traditional settlement situation and countermeasure of Zhengzhou new urbanization four community" (project number: 141PXKXF612). its connotation and spirit, only integrating elements of aesthetics of traditional architectural ornament can we apply cultural connotation to modern residential architectural form better. So the root of solving the problem is to study decorate characteristics of traditional dwelling houses in central plain of China deeply.

\section{LAW OF BEAUTY IN FORM OF ARCHITECTURE IN CENTRAL Plain OF China}

\section{A. Balanced Spatial Arrangement}

Symmetry, also called reciprocity, is the absolute equity formed by syntagmatic relation which is composed of similar or same factors of things, it is an absolute performance of law of equilibrium. Symmetry is divided into three kinds: central symmetry, symmetry of axis lines and plane symmetry. The symmetric form of things makes people happy, symmetric and balanced layout produces solemn, stern, magnificent and simple artistic effect. Balance, also called the "equilibrium" is the relation of both opposite and unified similar things. Architectural composition usually adopts symmetric layout because of its high stability, while balanced structure could be stable in asymmetric space or form of decoration.

In spatial sequence of traditional residential buildings, balance is achieved mainly by groups combination among the compounds. Especially, the compounds use passageways and lane to connect each other, transition produced by doors and transform of space function make up ample spatial sequence. Buildings in Kang Baiwan Manor mostly are hard mountain building of two layers, its construction sequence spread out gradually from west to east, each independent courtyard layout is built according to the layout form of traditional Chinese architecture "longitudinal axis, and secondly the horizontal axis", housing 1 to 5 in the most north of main housing in the village are in this form, constituting special form of courtyard that combine courtyard and kiln.

From spatial arrangement, we can see that most of the central plains native buildings and state of equalisation whose conditions are mostly axial symmetric, it usually is longitudinal axisymmetric of mirror type. But this type is not absolute symmetry, it follows traditional concept that high in east and low in west in building height and follows the principle adjusting measures to different conditions, 
influenced by this, rooms in the yard are mostly high in east and low in west.

\section{B. Symmetry of Architectural Form}

Such as Kang Baiwan Manor, because of its specific historical background, buildings carried characteristics of official buildings and civil buildings. the overall layout of buildings is symmetric and unified, decoration of eaves in and outside usually adopts symmetric layout and symmetric decoration, such as rockey pillow stone, wooden sparrow brace and brick carvings Chitou (one kind of decoration, used to water drainage and resistance) etc.

1) Display of diversity and unity. Contrast and unity is basic law of beauty in form and is followed by kinds of arts. By diversity, it means there should be different and distinct in the form of architectural decoration; by unity, it refers to common features or related and reflected relationships. Diversity without unity makes decoration disorderly and unsystematic, while unity without diversity makes decoration formalistic and monotonous. Both unity and diversity requires change, showing beauty of diversity and unity in change, showing internal harmony of unified adornment form. They are uniform in nature bur we should fully demonstrate their unique and implied meaning.

In building complex of Kang Baiwan Manor, owning to different usage, independent buildings have their own character and different decorative contents. We can find difference from their structures. There are also contrasts between shapes, colors and materials, but they imply unified cultural connotation and spiritual pursuit. At same time, their decoration change slightly such as curves on roof, side corner of the wall, Shengqi (a kind of architectural means) and adornments of the end, especially the adornments of the end, they are symmetric in form and different in contents.

2) Control of proportion and dimension. Proportion refers to quantitative relation between whole and part or among parts of the thing. All things have appropriate proportion in a certain range of dimensions. Beauty of proportion is produced in dimension, which means standard and specification including beauty of characteristics of thing itself. The size of the human body itself is the basic dimensions and internal factors to measure proportion of other beautiful things. Proportion is not set in stone, we can change proportion to create particular aesthetic effect.

3) Harmony of rhythm and beat. In the ornament of courtyard and buildings in Kang Baiwan Manor, we can easily find the sequence of architectural space and beat sense of space and door interval. From exterior space tio inner space of the architecture, lane functioned to space turn, gate of yard functioned as barrier and floor mounting hood, all make space cadent and sense the dynamic effect of the actual situation. Independent buildings in each yard are unity in architecture and decoration with little change to meet the demand of rhythm. In Kang Baiwan Manor, adjusting decoration form in details to give yards enough open space when transited and retain privacy at the same time.

\section{Diverse Decorative Form, Unified Decorative Connotations}

There are plenty of decoration grain types in Kang Baiwan Manor including animals, plants, figure, birds and beasts, drama stories and historical fables. such as plum blossoms, orchid, bamboo and chrysanthemum, luck and wealth and long-lived and happy wishes, the eight immortals of light and shade, Kirin Song Zi, Double lion dancing rope and so on. Abundant decoration grain types added clever construction techniques makes the architecture full of the milk of human kindness and regional culture.

Various decorative forms imply best wishes of being happy, long-lived, health and safe. From ancient times to today, Chinese regard happiness as the ultimate goal they pursue, therefore, Billiken comes into being. Just as the meanings of heaven god, earth god and water god in Taoism, they symbolize a gift of happiness, Good fortune and Blessings. Especially to central plains regions centered on agricultural civilization, "Fu" is a direct and social way to pray for native people.

\section{ACtUAl Design Practice of ARChitecture IN CENTRAL Plain OF CHINA}

\section{A. Modern Application of Rural Materials like Adobe}

Central China pays attention to adjusting measures to local conditions and using tools to materials, this is one reason why Chinese local-style dwelling houses have typical regional culture characteristics. While modern cities pay much attention to economic factors because choosing building materials, they prefer materials of good quality but cheap and convenient is also a principle in design of architecture decoration. Henan area, located in the middle and lower reaches of the Yellow River with fertile loess, is beneficial to use adobe and brick and tile for us. Adobe could use a long time because it is durable and easily maintained, in addition, it is environment friendly, which can't be matched by modern construction and decoration materials like rebar and cement.

By studying characteristics of forms of architecture and decoration in Kang Baiwan Manor, we find that in the traditional dwelling houses, building materials are mainly stones, woods, bricks, tiles and soil, constructing buildings with these basic materials could also get a good artistic effect. Therefore, the final effect is not totally decided by price of building materials, but by how they are applied and what kinds of building types they formed, match between materials and use. These provide very good reference on the choice of material for modern residential architecture design.

Most of the building complex in Kang Baiwan Manor are more than one hundred years, their decorative forms are full of cultural connotation as well. Buildings kept here are mainly with excellent architecture forms, their walls are built by brick with adobe in them, making the most parts of buildings intact, giving us enough space to decorate in them. When going around in the complex, we will find adobe wall type of cheap building decoration materials in the traditional local-style dwelling houses building construction and 
decorative components are perfect. We can find traditional architecture techniques combining modern means of science and technology apply to most primary, ecological and common decorative materials to modern new vernacular architecture, playing a role in the sustainable development of the research of modern dwelling architecture decorative design and development.

\section{B. Ingenious Design of Transitional Space like Yard}

The utilization of architecture space form follows the Chinese ancient philosophy principle "The Harmony between Man and Nature". Chinese humanistic spirit stresses that the human and the nature coexist harmoniously, so traditional dwellings could form a balanced relationship with nature. Whether in site selection or construction, traditional dwellings embody the respect for nature and harmonious coexistence with the environment all the time. All constructions are carried according to environment conditions, destroy the natural environment as little as possible and try their best to recycle the materials. All of these demonstrate collective intelligence of Chinese nation.

The complementary yard space well solved problems of sunlight, ventilation, heat insulation and air purifying. Staying in the yard, one can really feel the breath of nature, and enjoy the harmony between man and nature. Moreover, traditional dwellings are built under the principle functionality and economical efficiency, so the utilization of natural resources and energy is environmental friendly.

\section{Multifunctional Utilization of Architecture Decorative Components}

Architecture decorative components in Kang Baiwan Manor are with exquisite carving craft and profound cultural connotation. By analyzing their decorative forms and implied meanings and analyzing the decorative components of different functions in building complex of Kang Baiwan Manor, we can find their common usage pattern.

First, according to implied meanings and implicit contents of the decorative components, we can apply them to the modern house or other building decoration design, such as villa front door decoration, construction decoration or building exterior decoration form, and choose suitable according to the actual function of building decoration form.

Second, selecting according to the using parts of decorative form. For example, Buildings constructed in a new type, in order to show construction content better of the new building, we can choose the suitable decoration form or choose suitable decoration parts for decoration, thus makes people who see this building understand the contents of building from appearance, and grasp the new building the decoration, color, content, form and scale, experience sense of cultural connotation of construction.

\section{CONCLUSION}

The study of how to protect regional architecture is one important aspect of regional architecture culture, especially in the distribution pattern of Chinese traditional rural architectures and urban architectures, Henan occupies important history position, which is of great significance in protecting Henan traditional architectural culture. As the material witness of Henan glory history in middle and late feudal society, Henan historic buildings dominate the indispensable status in the formation and evolution of central plains culture and architectural culture.

\section{REFERENCES}

[1] Mao Bing. The Central Plains Culture and Contemporary Cultural Construction in Henan[M]. Zhengzhou: Henan people's publishing house, 2009

[2] Liu Dunzhen. Zhongguo Zhuzhai Gaishuo[M]. Tianjin: Baihua Literature and Art Publishing House, 2004.1

[3] Sun Dazhang. A Study of Chinese Dwellings[M]. Beijing: Chinese Building Industry Press, 2004.8

[4] Le Corbusie. To a New Building. Translated by Chen Zhihua[M]Xi' an:Shaanxi Normal University press, 2004.2

[5] Wang Qijun. Chapter 31 of Chinese Dwellings[M]. Beijing: Chinese Building Industry Press, 2005.11

[6] Cui Shichang. Modern Architecture and National Culture[M]. Tianjin: Tianjin University press, 2000.1

[7] Wang Hong. Application of Architectural form Characteristics of KangBaiWan Manor in Gongyi[D].Zhengzhou University of Light Industry, major art design, 2010.6 